\title{
We Measured and Have Expanded the Space for More Services in Digital Television
}

Paulo E. R. Cardoso

Yuzo lano

Diego A. Pajuelo

Raphael O. Barbieri 


\title{
We Measured and Have Expanded the Space for More Services in Digital Television
}

\author{
Paulo E. R. Cardoso, Yuzo Iano, Senior Member, IEEE, Diego A. Pajuelo, and Raphael O. Barbieri
}

\begin{abstract}
Digital TV stations transmissions can be configured so that the useful bit rate can accommodate a variable amount of information. We observed that the ISDB-Tb (Integrated Services Digital Broadcasting - Terrestrial, version B) bit rate is not fully utilized by the broadcasters. Hence, services can be added beyond to the content of television without this being hindered.
\end{abstract}

Index Terms- Bit rate, ISDB-Tb, Services, TV broadcasting

\section{INTRODUCTION}

$\mathrm{T}$ HE ISDB-Tb - Integrated Services Digital Broadcasting, Terrestrial, Version B - is the most flexible among the Digital Television standards in the world [1], and this feature provides to the broadcaster various possibilities of operation, and may go beyond standard audiovisual television content transmission.

Multi-program, additional audio channels, emergency alerts, electronic programming guide, notices of public utility, and interactivity are some of the options that the broadcaster may rely to attract more audience. But is there space available for all these services on TV channels?

This paper goes beyond the theoretical constraints. We use measures from some TV stations to show that these have configured its transmission systems in order not to maximize the use of bit rate and propose new ways of expansion and transmission capacity of the bit rate.

\section{ISDB-TB}

\section{A. The ISDB-Tb flexibility}

The ISDB-Tb was developed to allow video, audio, and data transmission, configuring, as its name says, a multimedia broadcasting system [1], which has technical flexibility for the most diverse types of content, with 3 three different types of reception: fixed, portable, and mobile [1].

This flexibility is reached due to the configuration of the transmission mode by means of the Number of Carriers; the Carrier Modulation; the Convolutional Code; and Guard Interval Width. The Standard [2] presents configurations allowed for the ISDB-Tb.

The Number of Carriers is linked to the amount of used OFDM carriers, being 1,405 for Mode 1; 2,809 for Mode 2; and 5,617 for Mode 3, causing the spacing between the carriers in approximately 4,2 , and $1 \mathrm{kHz}$ respectively, causing a slight difference in the bandwidth of each mode of
5.575, 5.573, and 5.572 $\mathrm{MHz}$ for modes 1, 2, and 3, respectively [2].

The digital carrier modulations are DQPSK, QPSK, 16QAM, or 64QAM, where each possible setting affects the coverage of the station with more or less robustness. The Convolutional Code of $1 / 2,2 / 3,3 / 4,5 / 6$, or $7 / 8$, changes the redundancy in the error bit correction, causing changes in the rate of useful bits in each setting. The Guard Interval Width of $1 / 4,1 / 8,1 / 16$, or $1 / 32$ of the duration of the symbol, allows the increase or decrease the immunity of the multipath and serves in the planning of Single Frequency Network - SFN.

TABLE I

ISDB-TB CONFIGURATIONS

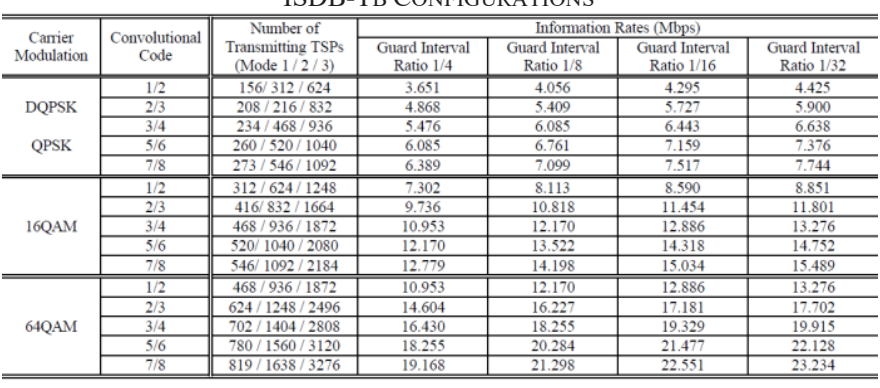

The broadcast engineer, who is responsible for setting the transmission mode, has to analyze what services will be available to the audience (one-seg, SDTV, EDTV, HDTV, multi-program, audio, data, etc.) and which network structure will be used (single transmitter or SFN), configuring then the transmission from those data, so that everything fit within the $6 \mathrm{MHz}$ available, and bearing in mind that the transmission mode that defines the available bit rate (Table I).

Despite being multimedia, the main purpose of the ISDB$\mathrm{Tb}$ is the transmission of audiovisual content of television, especially the high-definition content, adjusted for the resolution of 1920x1080 pixels at a ratio of 16:9. This content must be compatible with the restrictions imposed by H.264 High profile and level 4.0 (high@L4.0), or any other lower level and can be transmitted at bit rates up to $25 \mathrm{Mbps}$ [3]. However is possible to reduce more the bit rate thanks to video compression methods, assuring the same visual quality without noticeable distortion perceived by the viewer.

\section{B. Hierarchical Transmission}

The $6 \mathrm{MHz}$ of available spectrum for each channel is segmented into 14 parts (one of them being used for bandwidth guard) grouped into three hierarchical layers A, B, and $C$ [1]. Each layer can have a different number of

Y. Iano is a professor and coordinator of LCV - DECOM - FEEC - Unicamp (yuzo@decom.fee.unicamp.br).

D. A. P. Castro; R. O. Barbieri are MSc Candidates in Electrical Engineer, in Laboratório de Comunicações Visuais (LCV), do Departamento de Engenharia de Comunicações (DECOM), da Faculdade de Engenharia Elétrica (FEEC), da Universidade Estadual de Campinas (Unicamp) (perc@decom.fee.unicamp.br). researching in LCV - DECOM - FEEC - Unicamp (diegop@decom.fee.unicamp.br). 
segments, and they must respect the rule that the quantity of segments of the Layer A must be lesser than the Layer B, which also must be lesser than the Layer $\mathrm{C}$ [1]. One of the major innovations of the ISDB-T is to accept, for each layer, that the transmission modes can be configured differently, simplifying the adequacy of the transmission for the content to be sent [1].

Usually the central segment is reserved for the reception of mobile TV, forming the Layer A, using the most robust digital modulation (DQPSK/QPSK), which carry only 2 bits per symbol, causing the bit rate varies from 280.8 to $595.7 \mathrm{kbps}$, depending on the convolutional code and guard interval width [2]. The other 12 segments can be freely configured, leaving a useful bit rate from 3.3 to $21.4 \mathrm{Mbps}$ [2].

By way of comparison, in Japan, the country that has developed the ISDB-T System, most of the broadcasters would use only the configuration of modulation in 64QAM, convolutional code of $3 / 4$, and guard interval width of $1 / 8$ [1], causing the available bit rate for broadcasters, cover all the 12 segments dedicated to HDTV programming, would be fixed at $16.851 \mathrm{Mbps}$ [2].

The TMCC - Transmission and Multiplexing Configuration Control signal loads all the information of the transmission modes, and must be sent by a specific carrier to assist in the identification of the operating modes by receiver [2].

\section{Stations EVAluation}

To analyze if there are some space available, in terms of bit rate, in ISDB-Tb transmissions, so that would be possible to add more information and services, first at all we check how the TV broadcasters, which transmit content in high definition (HD) video, has configured the transmission modes for its station and observe how the available bit rate is being used. For that, it was used an ISDB-Tb professional receiver and a Transport Stream analyzer.

The ISDB-Tb professional receiver (EiTV DecoderIPBox) captures the digital TV channel, demodulates the signal and transmitting the entire content received via IP (TSoverUDP), including null packets of valid layers, i.e. all useful data rate of the signal. The stream of data is sent to the Transport Stream analyzer software (Dektec - StreamXpert), who extracts the transmission modes and separate the bit rates of each channel content.

In accordance with the measures extracted from TV stations, is possible to determine what is the bit rate not used and with this data, we propose new settings to make more efficiency the use of this bit rate. In this scenario, we will evaluate the possibilities for: the use of greater compression techniques in HD video; reconfiguration of transmission modes; and amendment of the hierarchical layers, aiming at the increase of its transmission capacity.

\section{RESUlTS}

Analyzing for about 5 minutes the transmissions of nine TV stations in the São Paulo/SP and Campinas/SP municipalities, on 06/03/2016, we observed that all stations use only two of the hierarchical layers, being the central segment the Layer A and the other 12 for the Layer B. Only four distinct configurations were used for Layer B: the A, C, and $\mathrm{E}$ stations use 64QAM modulation, convolutional code of $3 / 4$, and guard interval width of $1 / 16$; the $\mathrm{B}, \mathrm{D}, \mathrm{H}$, and I stations use 64QAM modulation, convolutional code of $3 / 4$, and guard interval width of $1 / 8$; the $\mathrm{F}$ station uses 16QAM modulation, convolutional code of $5 / 6$, and guard interval width of $1 / 16$; and the $\mathrm{G}$ station uses 16QAM modulation, convolutional code of $2 / 3$, and guard interval width of $1 / 8$, corresponding to the total bit rates of $18.3,17.3,13.6$, and $10.4 \mathrm{Mbps}$, respectively. We measured the transmission modes, the total bit rate of the channel (Channel), the bit rate used by HD video (VideoHD), and the rate of null PIDs (Null PID) (Table II). The Layer B column was determined from the parameters of transmission [2].

TABLE II

MEASURED CONFIGURATIONS AND BIT RATES

\begin{tabular}{|c|c|c|c|c|c|}
\hline Station & $\begin{array}{c}\text { Transmission } \\
\text { Modes }\end{array}$ & $\begin{array}{c}\text { Channel } \\
\text { (Mbps) }\end{array}$ & $\begin{array}{c}\text { Layer B } \\
\text { (Mbps) }\end{array}$ & $\begin{array}{l}\text { VideoHD } \\
\text { (Mbps) }\end{array}$ & $\begin{array}{c}\text { Null } \\
\text { PID } \\
\text { (Mbps) }\end{array}$ \\
\hline $\mathrm{A}$ & 64QAM - 3/4 - 1/16 & 18.3 & 17.8 & 15.2 & 2.0 \\
\hline B & $64 \mathrm{QAM}-3 / 4-1 / 8$ & 17.3 & 16.9 & 15.6 & 1.0 \\
\hline $\mathrm{C}$ & $64 \mathrm{QAM}-3 / 4-1 / 16$ & 18.3 & 17.8 & 11.8 & 4.0 \\
\hline D & $64 \mathrm{QAM}-3 / 4-1 / 8$ & 17.4 & 16.9 & 10.5 & 5.9 \\
\hline $\mathrm{E}$ & $64 \mathrm{QAM}-3 / 4-1 / 16$ & 18.4 & 17.8 & 14.5 & 2.9 \\
\hline $\mathrm{F}$ & $16 \mathrm{QAM}-5 / 6-1 / 16$ & 13.6 & 13.2 & 8.7 & 3.6 \\
\hline G & $16 \mathrm{QAM}-2 / 3-1 / 8$ & 10.4 & 10.0 & 9.7 & 0.1 \\
\hline $\mathrm{H}$ & $64 \mathrm{QAM}-3 / 4-1 / 8$ & 17.3 & 16.9 & 14.2 & 1.7 \\
\hline I & $64 \mathrm{QAM}-3 / 4-1 / 8$ & 17.3 & 16.9 & 12.3 & 4.2 \\
\hline
\end{tabular}

The data shows that the VideoHD content uses bit rates that vary from 8.7 to $15.6 \mathrm{Mbps}$, while the transmission modes have been configured to allow useful rates from 10.0 to $17.8 \mathrm{Mbps}$, in a system that allows rates up to $21.4 \mathrm{Mbps}$ for 12 segments [2]. We can demonstrate, by means of column VideoHD of Table II, that broadcasters are using different video compressions and are not using the entire available bit rate.

It is worth noting that in addition to the content of HD video, there are other information transmitted by the broadcaster, such as audio channels to the main programming of television, subtitles, EPG, information of interactivity, and various data for the provision of TV service. The bit rate occupied by these other information was calculated by (2) and is presented in column Others of Table IV.

\section{DISCUSSIONS}

There is a percentage of the bit rate provided by the ISDB-Tb that is not used by the broadcasters. Analyzing the collected data, we observed that the column Null PID Bitrate presents the bit rate of null PIDs (Table III), i.e., packets with the PID 0x1FFF that are filled with 0xFF bytes (stuff bytes), simply because there was no content to send [4]. The addition of these data is necessary to maintain a constant bit rate. Thus, we can observe directly that it is already available from 0.1 to 5.9 Mbps.

On average, are directly available $2.8 \mathrm{Mbps}$ per station and the sum of the nine analyzed broadcasters totals $25.4 \mathrm{Mbps}$, which is greater than the total possible for a channel that has the 13 segments configured on your maximum rate, i.e., 23.234 Mbps [2]. And this spare bandwidth can be better exploited, making some changes in the modes of the transmission. 


\section{A. Expansion of the not used bit rate}

First, we analyzed the rates used by VideoHD. We found rates from 8.7 to $15.6 \mathrm{Mbps}$. According to [5] it is necessary to assess the issue of subjective quality perceived by the viewer with the change of HD video bit rate. A subjective evaluation of note 4 (5-point MOS), still corresponds to a video of good quality, that under these conditions it uses a bit rate of 8.0 to $16.0 \mathrm{Mbps}$ [5]. Thus, depending on the interest of the broadcaster to expand its transmission capacity, you can use higher video compression, without loss of the subjective quality of HD video.

As the bit rate of the HD video can be reduced up to $8 \mathrm{Mbps}$, without reduce the subjective quality, the gain that each station may obtain with this reduction was calculated (Table III).

TABLE III

IMPROVEMENT WITH VIDEO COMPRESSION

\begin{tabular}{cccc}
\hline \hline Station & VideoHD (Mbps) & $\begin{array}{c}\text { New VideoHD } \\
(\mathrm{Mbps})\end{array}$ & $\begin{array}{c}\text { New Null PID I } \\
(\mathrm{Mbps})\end{array}$ \\
\hline $\mathrm{A}$ & 15.2 & 8.0 & 9.2 \\
$\mathrm{~B}$ & 15.6 & 8.0 & 8.6 \\
$\mathrm{C}$ & 11.8 & 8.0 & 7.8 \\
$\mathrm{D}$ & 10.5 & 8.0 & 8.4 \\
$\mathrm{E}$ & 14.5 & 8.0 & 9.4 \\
$\mathrm{~F}$ & 8.7 & 8.0 & 4.3 \\
$\mathrm{G}$ & 9.7 & 8.0 & 1.8 \\
$\mathrm{H}$ & 14.2 & 8.0 & 7.9 \\
$\mathrm{I}$ & 12.3 & 8.0 & 8.5 \\
\hline \hline
\end{tabular}

We have reduced the bit rate of VideoHD to $8.0 \mathrm{Mbps}$ and the difference of the previous rate was added to the Null PID. We can say that all broadcasters won bit rate with the strategy of reducing the rate of HD video (New Null PID I column in Table III).

In relation to the reconfiguration of the transmission modes, if we apply the configuration that offers the highest bit rate per segment, i.e., Modulation at 64QAM, Code Convolutional 7/8 and Guard Interval Width of 1/32 [2], for each broadcaster analyzed, we observed that can also be obtained gains in terms of bit rate (New Null PID II column in Table IV).

TABLE IV

IMPROVEMENT WITH TRANSMISSION MODES

\begin{tabular}{cccccc}
\hline \multicolumn{6}{c}{ IMPROVEMENT WITH TRANSMISSION MODES } \\
\hline \hline $\begin{array}{c}\text { VideoHD } \\
(\mathrm{Mbps})\end{array}$ & $\begin{array}{c}\text { Layer A } \\
(\mathrm{Mbps})\end{array}$ & $\begin{array}{c}\text { Others } \\
(\mathrm{Mbps})\end{array}$ & $\begin{array}{c}\text { New } \\
\text { Layer B } \\
(\mathrm{Mbps})\end{array}$ & $\begin{array}{c}\text { New Null } \\
\text { PID II } \\
(\mathrm{Mbps})\end{array}$ \\
\hline $\mathrm{A}$ & 15.2 & 0.46 & 0.64 & 21.4 & 5.6 \\
$\mathrm{~B}$ & 15.6 & 0.45 & 0.25 & 21.4 & 5.5 \\
$\mathrm{C}$ & 11.8 & 0.46 & 2.04 & 21.4 & 7.6 \\
$\mathrm{D}$ & 10.5 & 0.55 & 0.45 & 21.4 & 10.4 \\
$\mathrm{E}$ & 14.5 & 0.56 & 0.44 & 21.4 & 6.5 \\
$\mathrm{~F}$ & 8.7 & 0.38 & 0.92 & 21.4 & 11.8 \\
$\mathrm{G}$ & 9.7 & 0.41 & 0.19 & 21.4 & 11.5 \\
$\mathrm{H}$ & 14.2 & 0.45 & 0.95 & 21.4 & 6.2 \\
$\mathrm{I}$ & 12.3 & 0.45 & 0.35 & 21.4 & 8.7 \\
\hline \hline
\end{tabular}

We calculated the data with the following equations:

$$
\text { Layer } A=\text { Channel }- \text { Layer } B
$$

$$
\text { Others }=\text { Layer } B-\text { VideoHD }- \text { Null PID }
$$

New Null PID II = New Layer B - VideoHD - Others

We observed a significant gain in the not used bit rate, as in the case of the station F that reached $11.8 \mathrm{Mbps}$, higher even than the bit rate used for VideoHD. However it is necessary to evaluate the costs of this gain, because if you would change the modulation from 16QAM to 64QAM, you lose strength in the transmission, which is directly related to the coverage of the station ( $\mathrm{F}$ and $\mathrm{G}$ stations). The increase of the Code Convolutional causes a reduction in terms of redundancy, allowing the occurrence of more bit errors, which also causes a reduction of the station coverage (All stations). The reduction in the guard interval width causes the reduction of the immunity to multipath, that in urban environments may cause zones of intersymbol interference, resulting in areas with no possibility of channel reception (All stations). In these cases it is necessary to evaluate how the coverage is reduced and if this loss can be compensated by an increase in the transmission power.

Finally, using the hierarchical layers possibilities from ISDB-Tb, we can split the layer B, composed of 12 segments, in layers B and C. Thus the not used bit rate of each broadcaster can be treated in terms of segments that are not used, allowing that these not used segments can be allocated in Layer B, and can even be reconfigured to increase the transmission capacity of these segments, by moving the used segments for the HD content to the Layer C, without it being necessary to reconfigure them, avoiding the problems with the reduction of coverage previously mentioned.

TABLE V

\begin{tabular}{|c|c|c|c|c|c|}
\hline Station & $\begin{array}{c}\text { Bit Rate } \\
\text { per } \\
\text { Segment }\end{array}$ & $\begin{array}{l}\text { Number } \\
\text { of unused } \\
\text { segments }\end{array}$ & $\begin{array}{c}\text { New } \\
\text { Layer B } \\
\text { (Mbps) }\end{array}$ & $\begin{array}{l}\text { New Layers } \\
\text { Configuration }\end{array}$ & $\begin{array}{c}\text { New } \\
\text { Null } \\
\text { PID III } \\
(\mathrm{Mbps})\end{array}$ \\
\hline A & 1.4869 & 1 & 1.8 & $\begin{array}{c}\text { A: } 1 \\
\text { B: } 1 \\
\text { C: } 11\end{array}$ & 2.31 \\
\hline B & 1.40429 & 0 & 0 & $\begin{array}{l}\text { A: } 1 \\
\text { B: } 12\end{array}$ & 1.0 \\
\hline $\mathrm{C}$ & 1.4869 & 2 & 3.6 & $\begin{array}{l}\text { A: } 1 \\
\text { B: } 2 \\
C: 10\end{array}$ & 6.11 \\
\hline $\mathrm{D}$ & 1.40429 & 4 & 7.1 & $\begin{array}{l}\text { A: } 1 \\
\text { B: } 4 \\
\text { C: } 8\end{array}$ & 11.6 \\
\hline $\mathrm{E}$ & 1.4869 & 1 & 1.8 & $\begin{array}{c}\text { A: } 1 \\
\text { B: } 1 \\
\text { C: } 11\end{array}$ & 3.21 \\
\hline $\mathrm{F}$ & 1.1014 & 3 & 5.4 & $\begin{array}{l}\text { A: } 1 \\
\text { B: } 3 \\
\text { C: } 9\end{array}$ & 7.9 \\
\hline G & 0.83217 & 0 & 0 & $\begin{array}{l}\text { A: } 1 \\
\text { B: } 12\end{array}$ & 0.1 \\
\hline $\mathrm{H}$ & 1.40429 & 1 & 1.8 & $\begin{array}{l}\text { A: } 1 \\
\text { B: } 1 \\
\text { C: } 11\end{array}$ & 2.1 \\
\hline I & 1.40429 & 3 & 5.4 & $\begin{array}{l}A: 1 \\
B: 3 \\
C: 9\end{array}$ & 8.2 \\
\hline
\end{tabular}

IMPROVEMENT WITH LAYERS RECONFIGURATION

Note that this reconfiguration proposal (New Null PID III column in Table V) can generate three situations: the first where it was not possible to create a third hierarchical layer, because the remainder of not used bit rate was smaller than the minimum bit rate of the segment (B and $G$ stations); the second, in which the gain is lesser than $1.0 \mathrm{Mbps}(\mathrm{A}, \mathrm{E}$, and 
$\mathrm{H}$ stations); and finally the third situation, where the gain in not used bit rate is greater than $2.0 \mathrm{Mbps}(\mathrm{C}, \mathrm{D}, \mathrm{F}$, and I stations).

It is worth noting that this reconfiguration needs to be evaluated on a case by case basis by the broadcast engineer, since the creation of the third hierarchical layer, with consequent new configuration of transmission modes can cause different areas of coverage, which already occurs between programming in one-seg (Layer A) and a high definition (Layer B).

Each of the proposed changes may affect some particular characteristic of the ISDB-Tb, therefore must be carefully studied to ensure that the expansion of the not used bit rate for the inclusion of new services does not affect the availability of the main signal of TV in its coverage area.

We observed in Fig. 1 that all the proposed techniques can be applied to maximize the space available for more services. In addition, the proposals mentioned that there are some alternatives between the techniques leaving to that the broadcast engineer could make the right decision to configure the system of the station.

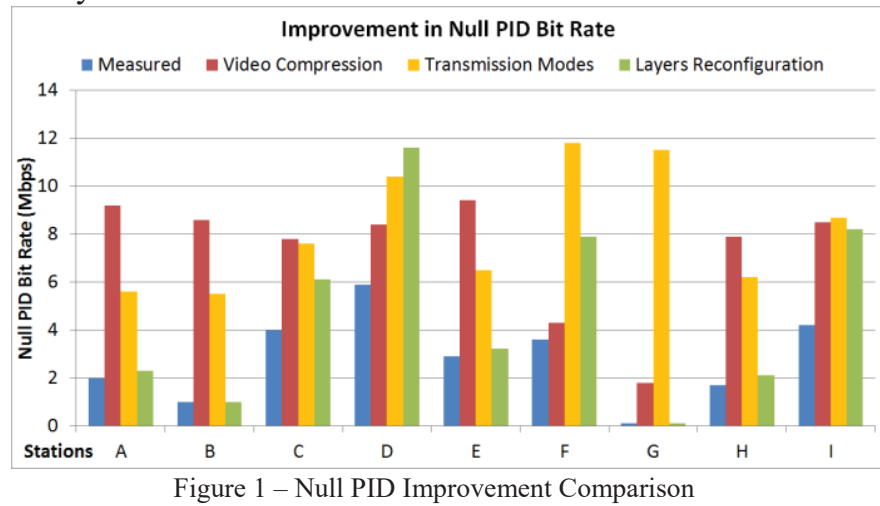

\section{CONCLUSIONS}

The TV broadcasters do not utilize the entire bit rate provided by the ISDB-Tb, either by not configuring the transmissions at the maximum rate permitted by the system, or even by not using the entire bit rate configured.

The bit rate not used may be increased, depending on the need of the TV broadcaster, changing it whether or not the current characteristics of coverage, redundancy, and immunity to the multipath.

It is a TV broadcaster responsibility to evaluate the application of this not used bit rate, implementing other services in addition to the TV Service, or even, improving the robustness of your station.

\section{ACKNOWLEDGMENT}

The authors would like to tanks CAPES, CNPq, and Fapesp; also the other teachers and staff of DECOM, FEEC, and UNICAMP.

\section{REFERENCES}

[1] M. Takada and M. Saito, "Transmission systems for ISDB-T," Proceedings of the IEEE, Special Issue on Global Digital Television: Technology and Emerging Services, pp. 251-256, Jan. 2006

[2] ABNT NBR 15601 - Digital terrestrial television - Transmission System, 2007

[3] ABNT NBR 15602-1 - Digital terrestrial television - Video coding, audio coding and multiplexing - Part1: Video coding, 2007

[4] ITU-T H.222.0 - Information technology - Generic coding of moving pictures and associated audio information: Systems, 2014
[5] L. Polak, M. Slanina, T. Kratochvil and P. Pardo, "A Comparison of Single and Double Stimulus Subjective Assessment of Full HD Video Sequences," Proceedings of the IEEE on Radioelektronika 2014 24th International Conference, pp 1-4, Apr. 2014

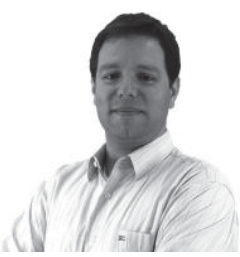

Paulo E. R. Cardoso Holds a degree in Electrical Engineering from the FEECUNICAMP (2002) and a MSc degree in Electrical Engineering (Electronics) by DEMIC-FEEC-UNICAMP (2005). He is currently a $\mathrm{PhD}$ candidate in the $\mathrm{LCV}$ DECOM-FEEC-UNICAMP, searching Digital TV. Licensed from the post of Specialist in Regulating in the Agência Nacional de Telecomunicações Anatel, where it operates in coordination of grants and resources to the provision, working with the licensing and amendment of technical characteristics of broadcasting stations. Previously, he served in the surveillance in broadcasters and in the solution of problems of radio interference in any system of telecommunication. He was responsible for the Technical Regulation to Broadcasting in Modulated Frequency and analysis of processes of technical feasibility for inclusion or amendment of the Basic Plan of Distribution Channels of Broadcasting in Modulated Frequency. He participated as an observer in the Federal Government in testing of Digital Radio Broadcasting, both in tests of American Standard - HD Radio, in 2008 and 2012, as in tests of the European standard - DRM, in 2010. He has worked as a telecommunications researcher of the Fundação Centro de Pesquisas e Desenvolvimento - CPqD.

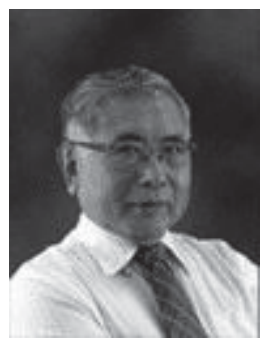

Yuzo Iano Prof. Yuzo Iano is the head and founder of the LCV since 1972 . He obtained his BSc (1972), MSc (1974) and $\mathrm{PhD}$ (1986) in Electrical Engineering at Unicamp, SP-Brazil. Research Interests: Digital Signal Processing (images/audio/video), Digital TV, 4G (LTE) and 5G Cellular Networks, Pattern Recognition, Smart Cities, Smart Grid, Internet of Things.

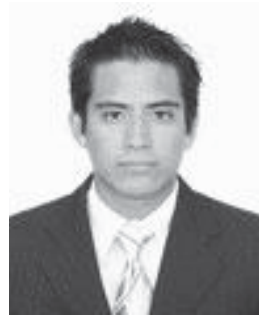

Diego A. Pajuelo Graduate in Electrical Engineering from the Peruvian University of Applied Sciences (UPC), Lima, Peru in 2012. He is currently working towards his Master degree in Sciences and Telecommunications at Unicamp.

Research Interests: Video and audio coding, Image processing, Digital television and Satellite communications.

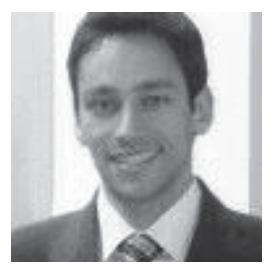

Raphael O. Barbieri Graduated in Computer Engineering from FEECUNICAMP (2007) and MBA in Project Management from IBE-FGV (2014). Member of Technical Module of SBTVD Forum and Product Manager at EiTV. He is currently working on his Master's degree in Electrical Engineering at FEEC- 
Unicamp. Research Interests: Digital TV, ISDB-Tb and Broadcast Engineering. 